Revue d'histoire de l'Amérique française

QREVUE D.HISTOIRE DE L'AMÉRIQUE FRANÇAISE

\title{
SIMARD, Jean, Le Québec pour terrain. Itinéraire d'un missionnaire du patrimoine religieux (Sainte-Foy, Les Presses de l’Université Laval, 2004), 242 p.
}

\section{Tania Martin}

Volume 59, numéro 1-2, été-automne 2005

URI : https://id.erudit.org/iderudit/012750ar

DOI : https://doi.org/10.7202/012750ar

Aller au sommaire du numéro

Éditeur(s)

Institut d'histoire de l'Amérique française

ISSN

0035-2357 (imprimé)

1492-1383 (numérique)

Découvrir la revue

Citer ce compte rendu

Martin, T. (2005). Compte rendu de [SIMARD, Jean, Le Québec pour terrain.

Itinéraire d'un missionnaire du patrimoine religieux (Sainte-Foy, Les Presses de

l'Université Laval, 2004), 242 p.] Revue d'histoire de l'Amérique française,

59(1-2), 189-190. https://doi.org/10.7202/012750ar d'utilisation que vous pouvez consulter en ligne.

https://apropos.erudit.org/fr/usagers/politique-dutilisation/ 
le dévouement ont toujours été reconnus, devront continuer à se contenter de piètres conditions de travail et de bien maigres salaires. De plus, leurs salaires demeureront longtemps très inférieurs à ceux de leurs homologues masculins.

Cependant, à partir des années 1940, la combativité syndicale croissante - combinée aux réformes qui marqueront la Révolution tranquille deux décennies plus tard - réussira enfin à faire accéder les institutrices à un véritable statut professionnel, leur permettant désormais de bénéficier de conditions de travail plus équitables. Mais, nous rappellent les auteures de l'ouvrage, les enseignantes estiment aujourd'hui que l'équité salariale, pour laquelle elles se sont tant battues, est encore loin d'être véritablement acquise. À cet égard, il s'agit donc d'un combat inachevé et... d'une histoire à suivre.

NADIA FAHMY-EID

Département d'histoire

Université du Québec à Montréal

SIMARD, Jean, Le Québec pour terrain. Itinéraire d'un missionnaire du patrimoine religieux (SainteFoy, Les Presses de l'Université Laval, 2004), 242 p.

Avec ce livre, Jean Simard nous présente une autobiographie intellectuelle et une généalogie professionnelle. Les textes recueillis pour ce $28^{\mathrm{e}}$ numéro de la collection Les Archives de Folklore proviennent de différentes périodes de sa carrière et sont organisés thématiquement en cinq chapitres: les trois premiers portent sur la religion populaire des catholiques au Québec, sur les pratiques et la culture matérielle religieuses de divers groupes ethniques (protestants francophones au Québec, catholiques au Mexique et en Bretagne) ainsi que sur le patrimoine religieux des Québécois catholiques tandis que l'avant-dernier traite de l'art populaire et que le dernier rend hommage aux pionniers des inventaires du patrimoine du Québec. En regroupant ainsi ses écrits, l'auteur dresse un portrait d'un domaine d'études situé au croisement de l'histoire et de l'ethnographie, tout en explorant une facette fondamentale d'une société : la religion.

L'ouvrage documente tant les aspects matériels qu'immatériels du patrimoine religieux au Québec et plaide aussi pour sa sauvegarde. Le contenu ratisse large quoique certaines idées se répètent. Pris ensemble, les écrits témoignent de l'évolution des réflexions de l'auteur et aussi des stratégies qu'il déploie pour construire et diffuser les savoirs et les savoir- 
faire par le biais d'articles scientifiques, de rapports de recherche, d'expositions, de communications et même de l'enseignement. Simard prône la recherche-action, ce qui favorise une dialectique entre l'observé et l'observateur. Cette approche demande la participation des gens du milieu dans des projets de recherche tout en offrant aux étudiants des activités de formation en situations réelles. Pour lui, c'est aussi la recette pour assurer un avenir au patrimoine religieux.

TANIA MARTIN

Département d'architecture Université Laval 